Article

\title{
Urban Land Expansion and Structural Change in the Yangtze River Delta, China
}

\section{Jinlong Gao ${ }^{1,4}$, Yehua Dennis Wei ${ }^{2,3, *}$, Wen Chen ${ }^{1}$ and Komali Yenneti ${ }^{1}$}

1 Key Laboratory of Watershed Geographic Sciences, Nanjing Institute of Geography and Limnology, Chinese Academy of Sciences, Nanjing 210008, China; E-Mails: jlgao@niglas.ac.cn (J.G.); wchen@niglas.ac.cn (W.C.); yenneti@niglas.ac.cn (K.Y.)

2 Department of Land Management, Zhejiang University, Hangzhou 310029, China

3 Department of Geography, University of Utah, Salt Lake City, UT 84112-9155, USA; E-Mail: wei@geog.utah.edu

4 University of Chinese Academy of Sciences, Beijing 100049, China

* Author to whom correspondence should be addressed; E-Mail: wei@geog.utah.edu; Tel.: +86-801-585-0545; Fax: +86-801-585-8218.

Academic Editor: Giuseppe Ioppolo

Received: 28 April 2015 / Accepted: 28 July 2015 / Published: 31 July 2015

\begin{abstract}
Urban development in China has attracted considerable scholarly attention. However, more work is still needed to examine and understand the mechanisms of urban land expansion, especially within the context of globalization/marketization, decentralization and urbanization. This paper analyzes urban land expansion and structural changes in the Yangtze River Delta (YRD). We find that cities in the YRD are experiencing urban land expansion mainly characterized by the growth of residential and industrial land. The dominant characteristics of urban land expansion in cities have also varied within different development and administrative levels. Based on our conceptual framework, we have used multi-models to investigate the driving forces of urban land expansion and structural changes in the YRD. The results reveal that six influencing factors - foreign direct investment (FDI), labor, government competition, institution, population, and job-housing relations - facilitate land use change in the economic transition process. However, their impacts differ in cities in different geographical locations, as well as with different administrative levels. Finally, this paper discusses policies to promote sustainable urban land use in the YRD.
\end{abstract}


Keywords: urban land expansion; economic transition; urbanization; Yangtze River Delta (YRD); China

\section{Introduction}

Over the past few decades, unprecedented urbanization, mainly driven by globalization, centralization, and marketization, has taken place in China. Between 1978 and 2013, the nation's urbanization rate has increased from $17.9 \%$ to $53.7 \%$. The rapid pace of urbanization has resulted in not only dramatic urban land expansion, but also issues such as environmental resources depletion, food deficits, and land degradation [1-3]. The socioeconomic and environmental problems, characterized by rapid urban land expansion, have become major challenges for achieving sustainable urban development (SUD) in China. In a step towards addressing the challenges and achieving SUD, the government of China has introduced the "National New-type Urbanization Plan" (NNUP), the country's first official plan on urbanization, in March 2014. The concept covers a wide ranging issues, including rural-urban integration, efficient use of land, and coordination between the drivers of regional development [4]. One of the major principles of the NNUP is to achieve sustainable urban land expansion, while emphasizing economic growth. A crucial prerequisite in the process of formulating sustainable urban development strategies within the NNUP is to understand the existing spatial development of urban land and the driving forces underlying the expansion [5]. It is, thus, significantly important to undertake a timely research that can not only document the structural changes of urban land, but also reveal the underlying mechanisms.

A rich body of literature is explored to uncover the patterns of urban land expansion in different cities of China [6]. The findings of the literature cover issues such as the patterns of built-up land expansion [7], the process of spatial restructuring [8], the mechanisms of urban growth [9], and the policy outcomes [10]. Although urban land expansion in China is well-documented throughout this academic literature, most of the literature is based either on single city or single province case-study contexts. Cross-city comparative studies on characterizing urban land expansion and its driving forces remain limited to date. Even the traditional theories have provided limited understanding on the rapid evolution of China's urban land use structure. Considering the significant heterogeneity, especially the different development and administrative levels, among the cities in China, it is important to conduct a comparative research on urban land expansion in different transitional cities. In context of the dearth of literature, the primary goal of this research is to examine and analyze urban land expansion and structural changes in the Yangtze River Delta (YRD), China, by focusing on the heterogeneity of cities in terms of the different development and administrative levels. The region's rapid urban development makes it an excellent case study to explore spatiotemporal urban land expansion patterns and retrospectively cross-compare urban growth drivers.

Apart from undertaking a study on the dynamics and mechanisms of urban land expansion in contemporary China, it is also essentially important to take into account the combined effect of influencing factors such as globalization/marketization, decentralization and urbanization. These triple processes can help to systematically (re)understand the mechanisms of urban land expansion during the 
transition era [11]. Given that NNUP is merely a start of the path towards reaching China's sustainable urban development destination, it is an opportune time to examine and reflect on these issues. To summarize, characterizing urban land expansion is a prerequisite to not only understand the urbanization process in China, its driving forces, and the socioeconomic consequences, but also to support the development of sustainable urban planning and management strategies [12].

\section{Literature Review}

\subsection{Sustainable Land Use in Regional Urban Development}

Since the 1980s, global economic transformations, stimulated by foreign investments, have not only "leap-frogged" economic development but also triggered significant changes in the process of urbanization. These transformations, through redefining the economic base of cities and recasting the spatial patterns in relation to new industrial and productive conditions, have facilitated the emergence of "region-based urbanization" [13]. A large amount of research within the new economic geography field has also emerged to understand urban land expansion in regions. Regional urban land expansion has attracted considerable scholarly attention both internationally and in China since it is threatening sustainable urban and regional development [14]. The research has provided an understanding on how the city influence is moving to wider regions, thanks to advances in technology, circulation of commodities, de-concentration of manufacturing, and diffusion between the urban and rural. The primary focus of this research area has largely been on three issues. First, to account the enduring urban land expansion and spatial changes, in the light of global economic transformations and information flows $[15,16]$. Second, to document the regional dispersion of population and manufacturing activities $[13,17]$. Last, to review the implications of the spatial structural changes on poverty and social functioning [18,19]. While sustainable land use development has been an important component in debates surrounding urban expansion [20], the literature provide limited guidance on what constitutes sustainable land use and how to achieve it.

Some of the clearer debates around sustainable land use are found in the academic work drawn on the "New Urbanism" movement. The movement, initiated at the Congress for the New Urbanism held in 1993, gives significant impetus to creating regions which improve the quality of life, while protecting the natural environment [21]. Since then, a large amount of academic scholarship concerning sustainable land use development has developed. Leccese et al. [22], in their Charter for the New Urbanism, identifies infill development as a means of conservation of environmental resources, attracting economic investment, and balancing social fabric - the three interacting elements of sustainable land use development. They go further and argue that neighborhood mixed-use compactness allows for locally embedded institutional and commercial activities. According to Newman and Kenworthy [23], sustainable land use seeks to reconnect transport with other developments, and establish transit-oriented development where high-density and mixed-use areas are built around high-quality transit systems. Such a focused urban land use structure can help to loosen the grasp of automobile dependence and eventually achieve smart urban growth. In brief, the different arguments on New Urbanism emphasize high density, mixing of commercial and residential land use, convenient public transit, safe and public-friendly street 
networks, strategically placed open spaces, and neighborhoods designed to foster social interaction and a strong sense of place as common traits of sustainable land use development in regions [24].

Though these scholarly arguments based on different theoretical contexts have provided a new direction to the literature on "sustainable land use", there is a significant scope for exploring the following points: (i) the need for comprehensive frameworks that provide a meaningful understanding on urban expansion in multiple cities of regions; (ii) the complex dynamics of urban expansion and structural change in regions, and their linkages to patterns of economic activities and urban population; and (iii) the necessity for understanding the role of multiple forces in the expansion and spatial changes in regions.

\subsection{The Driving Forces of Urban Land Expansion}

In the arguments of urban land use and land expansion, different driving forces underlying the urban land expansion are identified. These include (i) demography or demands for space by people and employment $[25,26]$, (ii) the changing industrial landscape, with the growth of manufacturing and production facilities and associated working-class housing, services, and commerce to cater to those facilities [27,28], (iii) improvements in transportation networks (roads, public transport, etc.), changes in mobility patterns and transit-oriented development [29,30], and (iv) institutional factors, such as fragmentation in municipal jurisdictions and planning, and variations in tax structures [20,31].

Along with the international literature, wide ranging studies have emerged over the years to investigate the relationship between urban land expansion and its driving forces in China [32,33]. In spite of the large number of possible drivers, the majority of these studies operationalize on economic development and population growth, and to some extent, traffic and physical conditions [34,35]. Considering the complexities within China, it is preeminent to understand urban land expansion through multiple driving forces and in multiple city contexts. Friedmann [36] emphasizes that understanding the driving forces of urban land expansion in China only from an economic perspective is obviously simplistic and deterministic since it overlooks some of the fundamental social and political conditions. With the growing institutionalism and localism in economic development, scholars have attempted to apply elite and urban regime theories to understand urban land expansion in China [37]. They argue that there are three major interest groups and two coalitions in the process of urban land use development: (i) economic coalitions between urban government and market developers or investors, and (ii) political coalitions between the central and local governments [38].

Moving away from the Western urban expansion studies, scholars have recently provided new explanations regarding the process of urban land expansion in China. For example, Wei [11,39] has proposed a framework within which China's economic transition is a triple process of decentralization, marketization, and globalization. This framework provides an innovative basis for China's spatial structuring theory. Additionally, various other researchers have also investigated the effects of other factors on urban land expansion. While some scholars have demonstrated that China's urban growth is driven by economic, fiscal, and political incentives from local governments and local leaders who control land use in their jurisdictions [35,40,41], others have examined the processes of urban land expansion from the perspective of institutions, and foreign direct investment (FDI) [7,42]. Scholars also argue that 
the growth and spatial expansion of China's cities takes a path-dependent trajectory influenced by the legacy of socialist political and planning systems [43,44].

Though this line of research is very fruitful, and has documented patterns of urban land expansion in China, more efforts are still needed to examine the mechanisms of urban land expansion in regions under the new context of globalization/marketization, decentralization and urbanization. Most importantly, as driving forces may differ in various geographical scales and locations due to scale-dependency and geographical non-stationarity [45-47], a systematic understanding on the relation between urban land expansion and its multiple driving forces is necessary to deal with the challenges of rapid urbanization and sustainability facing China. Moving away from the traditional debates which emphasize urban expansion as a process that involves population redistribution and restructuring [13], we argue that urban expansion is a process that involves reconfiguration of multiple forces at multiple scales (local, regional, and global).

\section{Materials and Methods}

\subsection{The Conceptual Framework}

While different studies have identified a wide ranging external and internal forces that drive the mechanisms of urban land expansion processes [5,34,48,49], we have developed an integrated conceptual framework for this research based on Wei's analytical framework $[11,50]$ because it provides a comprehensive model with different mechanisms and driving forces. The urban land expansion, namely the outward expansion/accretion and the inner reconstruction/replacement, is related to the drivers of local citizen, urban government, and global market, and their interactions (Figure 1). First, within the context of urbanization, local citizens exert an impact on the residential and industrial land by way of population growth and "jobs-housing separation". The large assortment of consumption goods and services that cities offer leads to migration of people from small towns. With the increase of urban citizens, more land is required for residential areas [51]. Meanwhile, the development of transportation and communication technologies might lead to urban spatial mismatch by the way of "jobs-housing separation" [52-54]. All these forces, thus, result in changes in the demand structures of land.

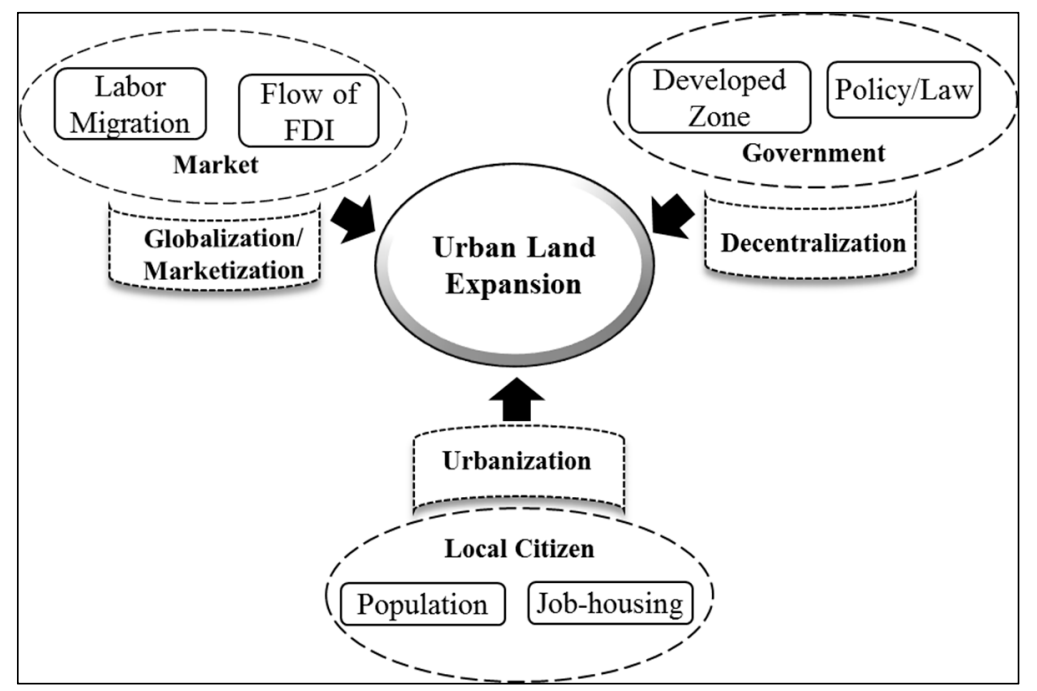

Figure 1. The conceptual framework of urban land expansion and restructuring. 
Second, the drive for development zones (DZ) is also an important factor in urban growth in China $[55,56]$. In the process of attracting both foreign and domestic investment, urban governments tend to establish more and more DZs in the outskirts, which often lead to the agglomerated development of industrial land [57]. Along with the establishing of DZs, various scholars have confirmed that institutional changes, through land use "policies" [58] such as land use right and ownership [59], the tax-sharing reform of 1994 [60], and the housing commercialization reform [61], have great impacts on urban land expansion process in China [33].

Third, due to inter-regional trade in the context of globalization and marketization, an increasing amount of FDI is being attracted into China. Consequently, industrial production spaces have sprawled at an alarming speed, which then stimulated the demand for real estate and public utilities at the newly expanded outskirts [62]. To cater the labor-intensive industrial activities, labor has migrated from both large cities and rural areas. Coincidently, the deepening of new international division of labor (NIDL), promoted by the formation of global production networks (GPNs), has also contributed to the transformation of regional economy from an industrial composition to a value-added economy in China [63]. As a result, not only local economy structures have drastically transformed, but also the urban land use structures.

The hierarchical structure of China's urban administrative system and urban land use, which are very different from the western counterparts, exerts strong influence on local development [64]. This strong role of urban hierarchical administrative system on the local land use planning and land administration emphasizes how the significant driving forces of the land development are also influenced by the urban hierarchical system or administration levels [14]. Hence, in this research, we have also taken geographical location and administration level into consideration.

Based on this conceptual framework, this paper is one of our systematic efforts to integrate globalization, institutional change, and China's new-type urbanization to better explain urban land expansion in the Yangtze River Delta (YRD) region, China's emerging global city region.

\subsection{Study Area, Data, and Methods}

Located in the YRD and adjacent to Shanghai, the study area is one of the three largest urban agglomerations, the other two being the Pearl River Delta and the Jing-Jin-Ji regions. The study area covers about 76,322 square kilometers, which is approximately $68 \%$ of the YRD territory. The sample cities are located in central and southern Jiangsu (JS), and northern Zhejiang (ZJ), two of the most developed provinces in China. In 2009, the size of the area's economy, measured by Gross Domestic Product (GDP), has surpassed other metropolitan areas, such as the Pearl River Delta and the Beijing-Tianjin-Hebei metropolis. The land administrative system is a strategic component of land policy in most developing countries [65]. The specific question about administrative ranking and urban expansion in China is legitimate since Chinese cities are institutionalized under different administrative authorities [14]. According to the Constitution of China, administrative units are based on a three tier-system, dividing the nation into provinces, counties, and townships. However, two more levels are inserted in actual implementation: the prefectures, under provinces; and the villages, under townships. In terms of urban administration, the country is divided into provincial level cities directly administered by the Central Government, prefectures, and county-level cities. The four centrally administrated cities, Beijing, Shanghai, Tianjin, and Chongqing, are further subdivided into urban districts and counties. 
Prefectural level cities are subdivided into county-level cities, counties, and urban districts. Local governments at different structural hierarchies of the administrative divisions have different legislative powers on land administration. Counties are generally considered as rural areas in China. Thus, we have selected all of the cities in the YRD, excluding Shanghai and other counties (Figure 2).

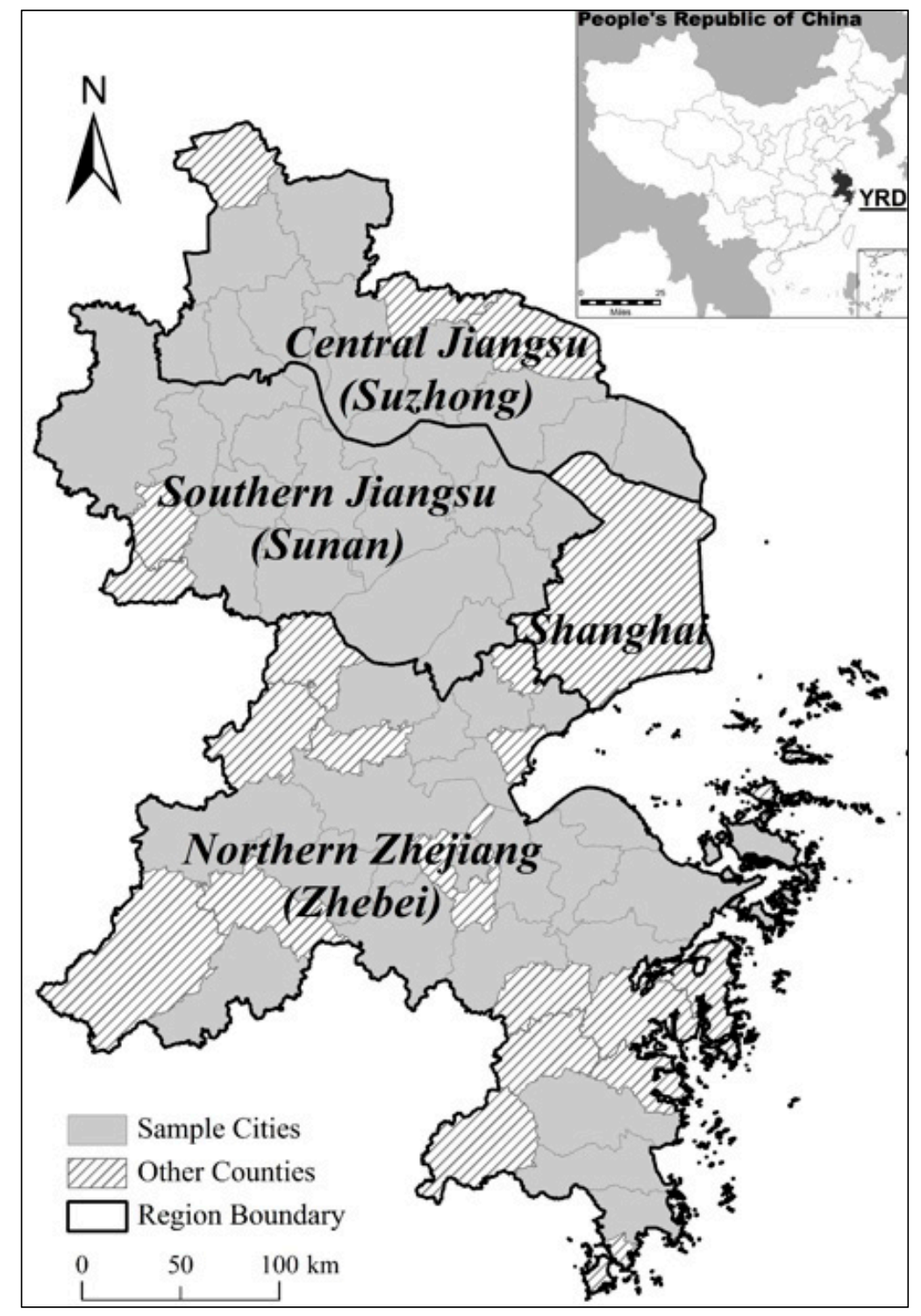

Figure 2. Location \& organization of study samples in the Yangtze River Delta, China.

As the administrative divisions have merged between 2000 and 2005, we have considered the sample cities consistent with the latest 2010 administrative units. The study area includes 15 prefectural level cities and 36 county level cities with a permanent population of 68.42 million in 2011 (Table 1). In 2011, the 51 sample cities together have produced more than 60,000 billion yuan of GDP (9523 billion USD). With an annual growth rate of 19\%, the regions' GDP per capita increased from 16,795 yuan (2029 USD) in 2000 to 87,700 yuan (13,920 USD). 
Table 1. Cities of prefectural and county levels in the YRD.

\begin{tabular}{lll}
\hline \multicolumn{1}{c}{ Regions } & \multicolumn{1}{c}{ Prefectural level cities } & \multicolumn{1}{c}{ County level cities } \\
\hline Central Jiangsu (Suzhong) & Nantong, Taizhou, Yangzhou & $\begin{array}{l}\text { Gaoyou, Haimen, Jiangdu, Jiangyan, Jingjiang, } \\
\text { Qidong, Rugao, Taixing, Xinghua, Yizheng }\end{array}$ \\
\hline Southern Jiangsu (Sunan) & $\begin{array}{l}\text { Changzhou, Nanjing, Suzhou, Wuxi, } \\
\text { Zhenjiang }\end{array}$ & $\begin{array}{l}\text { Changshu, Danyang, Jiangyin, Jintan, Jurong, } \\
\text { Kunshan, Liyang, Taicang, Wujiang, } \\
\end{array}$ \\
& & Yangzhong, Yixing, Zhangjiagang \\
\hline Northern Zhejiang (Zhebei) & Hangzhou, Huzhou, Jiaxing, Ningbo, & Cixi, Fenghua, Fuyang, Haining, Jiande, \\
& Shaoxing, Taizhou, Zhoushan & $\begin{array}{l}\text { Lin'an, Linhai, Pinghu, Shangyu, Shengzhou, } \\
\text { Tongxiang, Wenling, Yuyao, Zhuji }\end{array}$ \\
\hline
\end{tabular}

To analyze the urban land expansion process in the study area, various social and economic data from 2000 and 2010 statistical year books are used. We have also used the population data from the 2000 and 2010 Census of the People's Republic of China by county. The basic land use data is obtained from China Urban Construction Statistical Yearbooks (CUCSY) from 2000 to 2010. The CUCSY consists of nine land use types (residential, commercial \& business facilities, administration \& public services, industrial \& manufacturing, logistics \& warehouse, transportation, municipal utilities, green space and special-purpose land). Out of these, we have considered the structural changes and the growth of residential and industrial land due to their large shares in the overall urban land use.

According to our conceptual framework (Figure 1), variables representing urban land expansion, global market and local demographic drivers, and the proxy of government power are selected (Table 2). The areas of residential land, industrial land, and the whole built-up land for all prefectural and county level cities are used as dependent variables.

Table 2. The definitions of independent variables.

\begin{tabular}{ccc}
\hline Categories & Definitions & Abbreviation \\
\hline \multirow{2}{*}{ Globalization/Marketization } & Ln (foreign direct investment) & FDI \\
& Ln (labor) & Labor \\
\hline \multirow{2}{*}{ Decentralization } & Ln (level weighted number of DZs) & Policy \\
\hline \multirow{2}{*}{ Urbanization } & Ln (weighted sum strength of policy) & Citizen \\
& Ln (permanent citizens) & J-H \\
\hline \multirow{2}{*}{ Spatial \& Administration } & Southern Jiangsu (dummy) & Shebei \\
& Northern Zhejiang (dummy) & Prefecture \\
\hline
\end{tabular}

Based on the primary concerns of previous research [14,32], the $\log$ of foreign direct investment (FDI) is selected to understand if urban land use development is driven by the capital inflows or not. The $\log$ of labor reflects the migration of workers. We have used the level weighted (national level $=1.5$, provincial level =1) number of development zones to characterize the motivation of urban competition. The measurement of the strength of regional policies is calculated by the weighted sum strength of the different levels of policy. The number of permanent citizens is used to illustrate the level of urbanization. The jobs-housing separation index (the ratio of a city's share in the total of 51 sample cities to its share in residents) reflects the quality of urbanization. The variables for Southern Jiangsu (JS), Northern 
Zhejiang (ZJ), and prefecture are dummy variables and measure whether the city is located in the region itself, or is a prefecture. For Sunan, 0 means the city is not located in the Southern JS and 1 means the city is located in the Southern JS region; similarly for Zhebei. For Prefecture, 0 represents a county level city, and 1 represents that the city is a prefectural level city.

We have undertaken three modeling methods to spatially and temporally analyze the dynamics of urban land expansion in the YRD. First, Shannon's entropy $(H)$ and equilibrium degree $(E)$, denoted as Equations (1) and (2), are applied to measure the degree of dispersion or concentration of urban land use.

$$
\begin{gathered}
H=-\sum_{i}^{n}\left(P_{i}\right) \ln \left(P_{i}\right)=-\sum_{i}^{n}\left(S_{i} / \sum_{i}^{n} S_{i}\right) \ln \left(S_{i} / \sum_{i}^{n} S_{i}\right) \\
E=-\sum_{i=1}^{n}\left(P_{i}\right) \ln \left(P_{i}\right) / \ln (n)
\end{gathered}
$$

where, $P_{i}$ is the probability or proportion of occurrence of a phenomenon in the $i^{\text {th }}$ spatial unit out of $n$ units and, $S_{i}$ is the area of the $i^{\text {th }}$ land use type in one city with a total of $n$ types of land use. The equilibrium degree is the ratio of the actual value of entropy to its maximum value, and varies from 0 to 1. Furthermore, the difference of an index is defined as $D=1-E$, which can be used to reflect the dominance of urban land use. Cities with more land use types have higher entropy values.

Second, to understand the patterns of urban land expansion, regional land use change rates for both single land use type and comprehensive land use are computed [32]. In addition, Getis-Ord General $G$ and Getis-Ord $G_{i}{ }^{*}$ are employed to analyze the global and local patterns of urban land expansion process. The spatial analysis methods are employed to investigate the general dynamics of urban land expansion in the YRD. To explore the impacts of different factors in different regions and administration levels, we set three dummy variables as Southern Jiangsu, Northern Zhejiang, and Prefecture. The global pooled regression model is framed as the following Equation (3):

$$
y_{i t}=\sum_{k=1}^{K} \beta_{k i} \times x_{k i t}+\sum_{l=1}^{3} \sum_{m=1}^{M} \alpha_{l i} \times d_{l i} \times x_{m i t}+\sum_{l=1}^{3} \lambda_{l i} \times d_{l i}+u_{i t}
$$

where, $y_{i t}$ is the dependent variable value of region $i$ in the year $t$; $x_{k i t}$ is the value of variable $k$ of region $i$ in the year $t$; $d_{l i}$ is the regional or administration dummy variable of region $i$; $d_{l i} \times x_{m i t}$ is the cross variable; $\beta, \alpha$ and $\lambda$ are the coefficients to be estimated; and $u$ is the error.

To further identify the unique coefficient of each geographical unit, to avoid the heterogeneity of spatial effects, and to capture the spatially varying relationship between probability of land use conversion and explanatory variables in different years, we have applied geographically and temporally weighted regression (GTWR) [66]. The GTWR is calculated using the following Equation (4):

$$
y_{i}=\beta_{i}\left(u_{i}, v_{i}, t_{i}\right)+\sum_{k} \beta_{k}\left(u_{i}, v_{i}, t_{i}\right) X_{i k}+\varepsilon_{i}
$$

where $\beta_{i}$ is the constant parameter specific to each space-time location $i$ with a spatio-temporal coordinates of $\left(u_{i}, v_{i}, t_{i}\right) . \beta_{k}$ is the parameter of independent variable $X_{k}$ at location $i$.

The mechanisms of urban land expansion in the YRD are assumed to be sensitive to the cities' administrative ranks. Thus, the spatial regime model (SRM), a technique that can explicitly recognize the heterogeneity of land expansion mechanisms in different levels of cities, is employed [14]. Following the work of Cravo and Resende [67], we have allowed the coefficients to vary across two different regimes as shown in Equation (5): 


$$
\left[\begin{array}{c}
g r_{i, t A}^{*} \\
g r_{i, t B}^{*}
\end{array}\right]=\left[\begin{array}{cccc}
Y_{i, t-1 A}^{*} & X_{i, t-1 A}^{*} & 0 & 0 \\
0 & 0 & Y_{i, t-1 B}^{*} & X_{i, t-1 B}^{*}
\end{array}\right]\left[\begin{array}{c}
b_{A} \\
\varphi_{A} \\
b_{B} \\
\varphi_{B}
\end{array}\right]+\left[\begin{array}{c}
v_{i, t A} \\
v_{i, t B}
\end{array}\right]
$$

where the subscripts $A$ and $B$ indicate different regimes of prefectural level cities and county level cities, respectively; $g r_{i, t A}^{*}$ and $g r_{i, t B}^{*}$ are $\mathrm{N} \times 1$ column vectors with observations for urban land expansion for spatial regimes $A$ and $B ; Y_{i, t-1 A}^{*}$ and $Y_{i, t-1 B}^{*}$ are $\mathrm{N} \times 2$ matrices including the constant term and initial urban land expansion of each regime; $X_{i, t-1 A}^{*}$ and $X_{i, t-1 B}^{*}$ are the $\mathrm{N} \times \mathrm{K}$ matrices of observations on other explanatory variables for each regime; $v_{i, t A}$ and $v_{i, t B}$ are the $\mathrm{N} \times 1$ vectors of error terms.

\section{Results}

\subsection{Temporal Evolution of Urban Land Use Structure in the YRD}

In this section, we mainly analyze the temporal changes in residential, industrial, and the whole built-up land between 2000 and 2010. At an overall level, it can be observed that the residential land has increased from $448 \mathrm{~km}^{2}$ in 2000 to $868 \mathrm{~km}^{2}$ and $1180 \mathrm{~km}^{2}$ in 2005 and 2010, respectively (Table 3). However, the overall percentage remains unchanged at $28.1 \%$, thereby indicating the relatively consistent growth of residential land within the total urban sprawl. The proportion of industrial and manufacturing land to the overall land use has increased from $28.6 \%$ in 2000 to $29.3 \%$ in 2010 . This signifies the rapid expansion and high growth process of industries in the YRD. Another significant observation is that the land under municipal utilities has increased from $9.5 \%$ in 2000 to $10.8 \%$ and $12 \%$ in 2005 and 2010, respectively, indicating the development of both physical and social infrastructure.

Administratively, the industrial area increase of $363 \mathrm{~km}^{2}$ during 2000 to 2005, and the residential area increase of $221 \mathrm{~km}^{2}$ during 2005 to 2010 in prefectural level cities are the dominant observations. However, a decline in the land use under industrial land from $30.5 \%$ in 2005 to $29.7 \%$ in 2010 in prefecture level cities can also be observed. In county level cities, the residential land has decreased from $31.1 \%$ in 2000 to $30.5 \%$ in 2010 and the industrial land has increased from $28.1 \%$ to $29.0 \%$. It is also observed that the increase of municipal utilities in prefectural level cities is much faster than that in the county-level cities (Table 3). All these features indicate that cities with higher administrative hierarchies are in transition from producing to service cities, while the county level ones are still in the process of rapid industrialization. 
Table 3. Areas of main urban land use in 51 sample cities in 2000, 2005, and $2010\left(\mathrm{~km}^{2}\right)$.

\begin{tabular}{|c|c|c|c|c|c|c|}
\hline \multirow{2}{*}{ Urban Land Use Type } & \multirow{2}{*}{51 Cities } & \multicolumn{3}{|c|}{ Geographical Location } & \multicolumn{2}{|c|}{ Administration Hierarchy } \\
\hline & & Southern Jiangsu & Central Jiangsu & Northern Zhejiang & Prefecture & County Level \\
\hline \multicolumn{7}{|c|}{ Year 2000} \\
\hline Residential & $448(28.1)$ & $185(26.3)$ & $85(31.8)$ & $179(28.7)$ & $301(26.9)$ & $148(31.1)$ \\
\hline Administration \&Public Services & $185(11.6)$ & $88(12.5)$ & $29(10.8)$ & $68(10.9)$ & $128(11.5)$ & $57(12.0)$ \\
\hline Industrial \& Manufacturing & $455(28.6)$ & $209(29.7)$ & $85(31.8)$ & $161(25.9)$ & $322(28.8)$ & $133(28.1)$ \\
\hline Street and Transportation & $89(5.6)$ & $37(5.3)$ & $15(5.6)$ & $36(5.8)$ & $65(5.8)$ & $23(4.9)$ \\
\hline Municipal Utilities & $151(9.5)$ & $63(9.0)$ & $22(8.3)$ & $66(10.5)$ & $107(9.6)$ & $44(9.3)$ \\
\hline Green Space & $164(10.3)$ & $85(12.1)$ & $16(6.0)$ & $63(10.0)$ & $115(10.2)$ & $49(10.4)$ \\
\hline \multicolumn{7}{|c|}{ Year 2005} \\
\hline Residential & $868(28.1)$ & $427(27.5)$ & $129(32.5)$ & $312(27.3)$ & $601(26.8)$ & $266(31.1)$ \\
\hline Administration \& Public Services & $351(11.4)$ & $174(11.2)$ & $44(11.1)$ & $133(12.6)$ & $259(11.6)$ & $92(10.9)$ \\
\hline Industrial \& Manufacturing & $927(30.0)$ & $489(31.6)$ & $119(30.1)$ & $318(27.8)$ & $685(30.5)$ & $242(28.6)$ \\
\hline Street and Transportation & $137(4.4)$ & $68(4.4)$ & $18(4.7)$ & $50(4.4)$ & $102(4.6)$ & $35(4.1)$ \\
\hline Municipal Utilities & $334(10.8)$ & $161(10.4)$ & $39(10.0)$ & $133(11.7)$ & $243(10.8)$ & $91(10.8)$ \\
\hline Green Space & $321.3(10.4)$ & $161(10.4)$ & $28(7.1)$ & $133(11.7)$ & $236(10.5)$ & $85(10.1)$ \\
\hline \multicolumn{7}{|c|}{ Year 2010} \\
\hline Residential & $1180(28.1)$ & $551(27.5)$ & $194(32.5)$ & $436(27.3)$ & $822(27.2)$ & $359(30.5)$ \\
\hline Administration \& Public Services & $477(11.4)$ & $229(11.4)$ & $71(11.9)$ & $178(11.2)$ & $351(11.6)$ & $127(10.8)$ \\
\hline Industrial \& Manufacturing & $1229(29.3)$ & $601(30.0)$ & $180(30.2)$ & $447(28.0)$ & $897(29.7)$ & $332(29.0)$ \\
\hline Street and Transportation & $172(4.1)$ & $83(4.2)$ & $16(2.6)$ & $73(4.6)$ & $131(4.3)$ & $41(3.5)$ \\
\hline Municipal Utilities & $506(12.0)$ & $226(11.3)$ & $69(11.5)$ & $211(13.3)$ & $375(12.4)$ & $131(11.1)$ \\
\hline Green Space & $439(10.5)$ & $224(11.2)$ & $47(7.9)$ & $167(10.5)$ & $300(9.9)$ & $139(11.8)$ \\
\hline
\end{tabular}


The development level analysis infer that the cities in Central Jiangsu (JS) always have a higher percentage (more than 30\%) of residential land than that of cities in the Southern JS and Northern Zhejiang (ZJ) provinces. The domination of residential land expansion indicates the relatively slow industrial development in Central JS. The increase of industrial land percentage from $25.9 \%$ in 2000 to 28\% 2010 in Northern ZJ (Table 3) shows the rapid industrial expansion of the cities in this sub-region. While in the most developed Southern JS, industrial land along with the residential land has sharply increased during the first five years and then decreased in the following years. This demonstrates that the Southern JS province is leading the YRD region in terms of both industrialization and urbanization. Geographically, three significant growth poles are observed in the study area during 2000 to 2005 . They are Suzhou and Nanjing in the Southern JS and Hangzhou in the Northern ZJ province. In the period of 2005 to 2010, the hot spot of Hangzhou shifted to Ningbo (Figure 3).

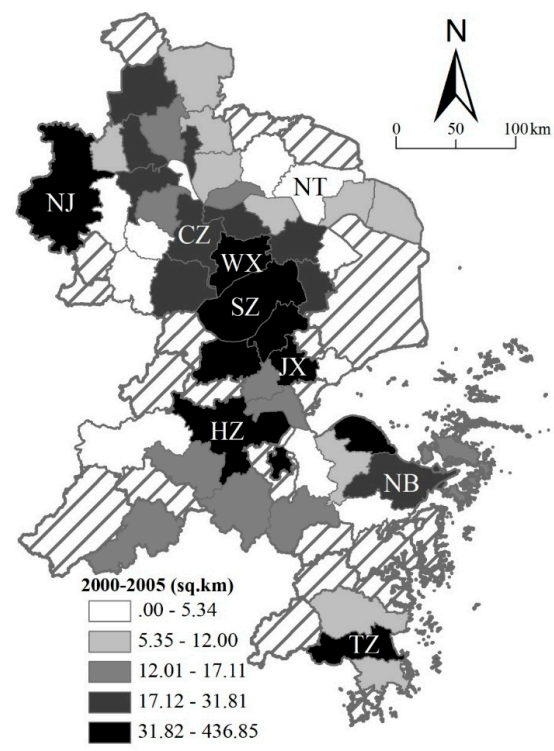

(A)

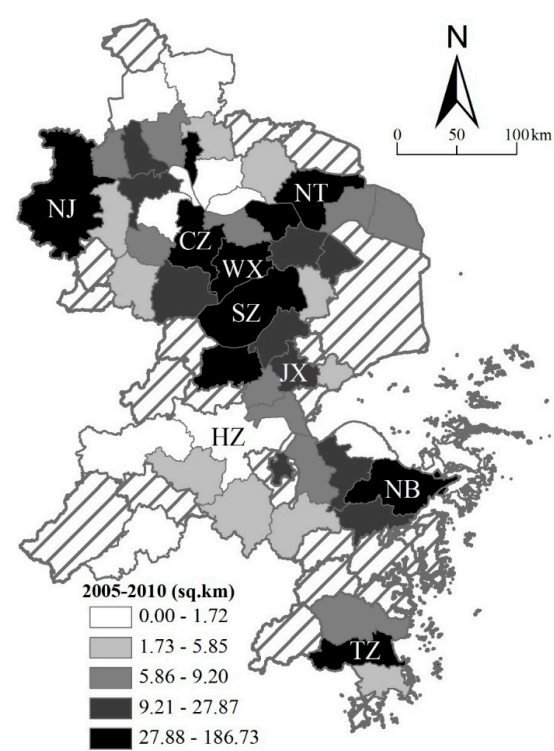

(B)

Figure 3. Built-up area growth in 51 sample cities, (A) 2000 to 2005 and (B) 2005 to 2010. $(\mathrm{NJ}=$ Nanjing, $\mathrm{HZ}=$ Hangzhou, $\mathrm{SZ}=$ Suzhou, $\mathrm{WX}=$ Wuxi, $\mathrm{CZ}=$ Changzhou, $\mathrm{NB}=$ Ningbo, $\mathrm{JX}=$ Jiaxing, $\mathrm{NT}=$ Nantong, $\mathrm{TZ}=$ Taizhou.)

In order to unfold the overall changes of urban land use structure in the YRD, we have further computed the Shannon's entropy $(H)$, equilibrium degree $(E)$ and dominance $(D)$. Through this, we find the equilibrium and complexity degree of urban land use structure in cities with different administrative hierarchies and geographical locations for the period 2000 to 2010. The results (Table 4) show that, for all the 51 cities, the values of $H$ and $E$ have decreased from 1.92 and 0.87 in 2000 to 1.83 and 0.83 in 2005 , respectively. However, for the same period, the $D$ value has increased from 0.13 to 0.17 . A similar trend can be observed in both the prefecture and county level cities. This indicates that though the dominant trends vary in different cities, urban land change has always been dominated by one or two types. Similarly, between 2000 and 2005, the values of $H$ decreased by $0.07,0.01$ and 0.14 in Southern JS, Central JS, and Northern ZJ, respectively. However, the dominant trend of urban land growth has stopped or even changed in Southern JS and Northern ZJ after 2005 with the Shannon's entropy remaining unchanged and increasing by 0.05 , respectively. It manifests that cities in the developed 
Southern JS are gradually optimizing their urban land use structure to be more coordinated and mature. The gaps between cities with different development levels have begun to shrink.

Table 4. The entropy of urban construction land in the sample cities, 2000 to 2010.

\begin{tabular}{ccccccccccc}
\hline \multirow{2}{*}{ Region } & \multicolumn{3}{c}{ Shannon's Entropy } & \multicolumn{3}{c}{ Equilibrium Degree } & \multicolumn{3}{c}{ Dominance Index } \\
\cline { 2 - 10 } & $\mathbf{2 0 0 0}$ & $\mathbf{2 0 0 5}$ & $\mathbf{2 0 1 0}$ & $\mathbf{2 0 0 0}$ & $\mathbf{2 0 0 5}$ & $\mathbf{2 0 1 0}$ & $\mathbf{2 0 0 0}$ & $\mathbf{2 0 0 5}$ & $\mathbf{2 0 1 0}$ \\
\hline Southern JS & 1.91 & 1.84 & 1.84 & 0.87 & 0.84 & 0.84 & 0.13 & 0.16 & 0.16 \\
Central JS & 1.82 & 1.81 & 1.75 & 0.83 & 0.82 & 0.80 & 0.17 & 0.18 & 0.20 \\
Northern ZJ & 1.95 & 1.81 & 1.86 & 0.89 & 0.83 & 0.85 & 0.11 & 0.17 & 0.15 \\
Total 51 Cities & 1.92 & 1.83 & 1.84 & 0.87 & 0.83 & 0.84 & 0.13 & 0.17 & 0.16 \\
Prefecture & 1.95 & 1.86 & 1.85 & 0.89 & 0.85 & 0.84 & 0.12 & 0.15 & 0.16 \\
County level & 1.85 & 1.73 & 1.80 & 0.84 & 0.79 & 0.82 & 0.16 & 0.21 & 0.18 \\
\hline
\end{tabular}

Coincidentally, the values of $H$ for the prefecture and county level cities decreased from 1.95 and 1.85 in 2000 to 1.86 and 1.73 in 2005 , respectively. The increase of the value of county level cities to 1.80 in 2010 indicates the halt of the dominant trend of urban land expansion. Furthermore, the fact that the prefecture level cities have bigger entropies than their county level counterparts confirms the hypothesis that land use structures in bigger cities are more complicated and less dominated [69]. However, the entropy of prefecture level cities decreased from 1.95 in 2000 to 1.86 and 1.85 in 2005 and 2010, respectively. On the contrary, the entropy of county level cities declined from 1.85 in 2000 to 1.73 in 2005 and then increased to 1.80 in 2010 (Table 4), leading to a narrowing gap.

\subsection{Spatial Pattern of Urban Land Expansion in the YRD}

In this section, the results from the analysis of spatial patterns of urban land use change, and in particular the changes in residential and industrial land in the 51 sample cities, through the global Getis-Ord $G$, are discussed. As illustrated in Table 5, the observed values of $G$ for all three change rates are greater than their mathematical expectations. Furthermore, while the $Z$ scores for change rates of the total urban land and residential land during 2000 to 2005 are significant, the change rate of industrial land is not. This result implies that in the first five years change rate of urban land is clustered, and urban land use change, especially for the residential land, has mainly occurred in the several active cores. Due to the widespread expansion of industrial land in the YRD, the clustering pattern disappeared in the later periods. After 2005, the $Z$ score for the change rate of the total urban land became insignificant, thereby indicating that a particular hot spot of urban land use change gradually disappeared. In contrast, the hot spots of residential and industrial land changes during this period still exist.

Table 5. The Global Getis-Ord $G$ of urban land expansion in 51 sample cities.

\begin{tabular}{ccccccc}
\hline \multirow{2}{*}{ Change Rate } & \multicolumn{3}{c}{$\mathbf{2 0 0 0 - 2 0 0 5}$} & \multicolumn{2}{c}{$\mathbf{2 0 0 5}-\mathbf{2 0 1 0}$} \\
\cline { 2 - 7 } & $\boldsymbol{G ( \times \mathbf { 1 0 } ^ { - \mathbf { 2 } } )}$ & $\boldsymbol{E}\left(\times \mathbf{1 0}^{-\mathbf{2}}\right)$ & $\boldsymbol{Z}$ Score & $\boldsymbol{G}\left(\times \mathbf{1 0}^{-\mathbf{2}}\right)$ & $\boldsymbol{E}\left(\times \mathbf{1 0}^{-\mathbf{2}}\right)$ & $\boldsymbol{Z}$ Score \\
\hline Residential land & 2.15 & 2.00 & 1.20 & 2.25 & 2.00 & 1.25 \\
Industrial land & 2.09 & 2.00 & 0.02 & 2.29 & 2.00 & 1.13 \\
Build-up areas & 2.19 & 2.00 & 2.01 & 2.10 & 2.00 & 0.96 \\
\hline
\end{tabular}

Note: $G=$ observed value of $G ; E=$ mathematical expectation of $G ; Z=$ standardized form of $G$. 
In order to uncover the spatial distribution of the hot spots and their change, the local Getis-Ord $G_{i}{ }^{*}$ values are calculated. The following are the results from the spatial analysis of the Getis-Ord $G_{i}{ }^{*}$ (Figures 4 and 5):

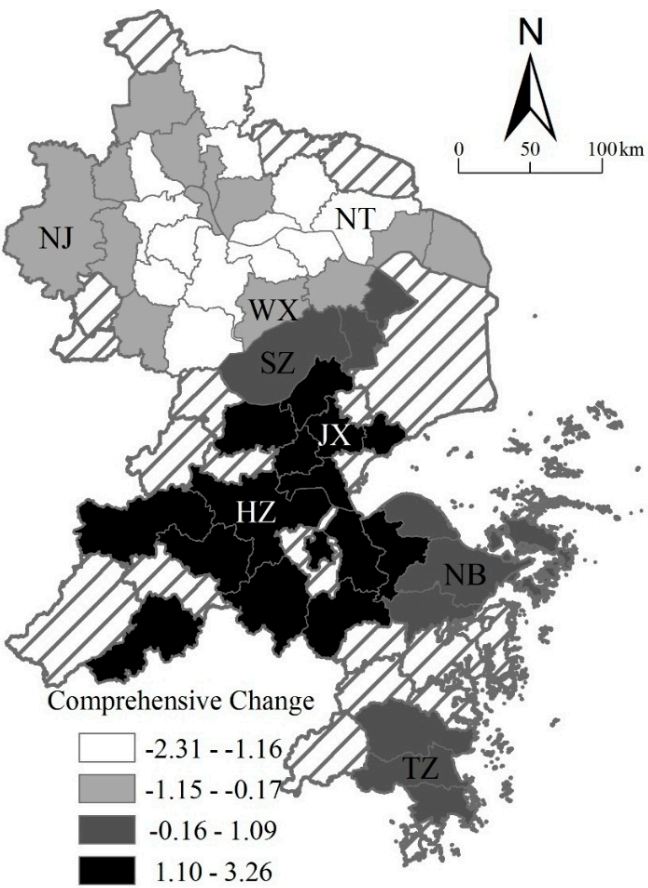

(A)

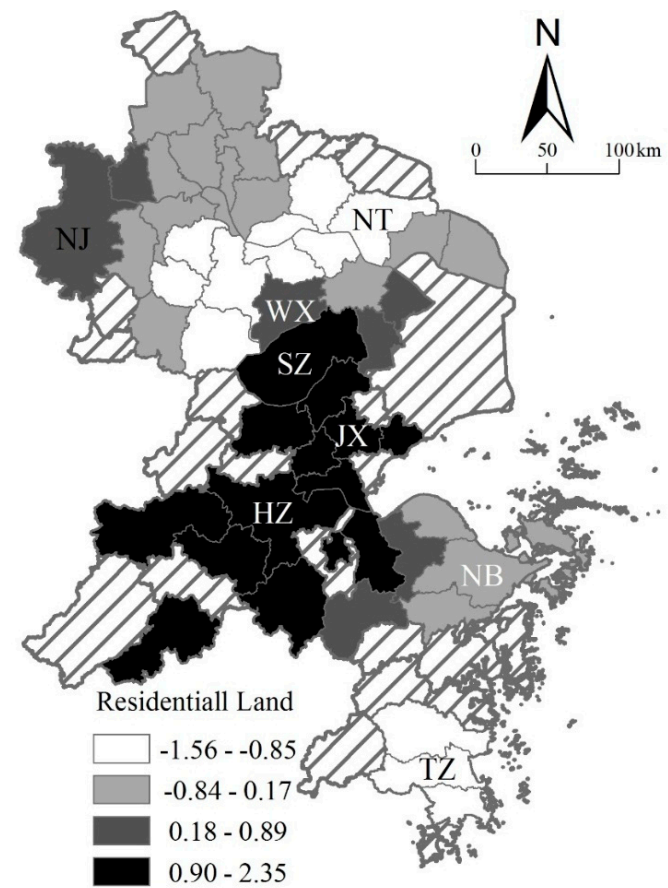

(B)

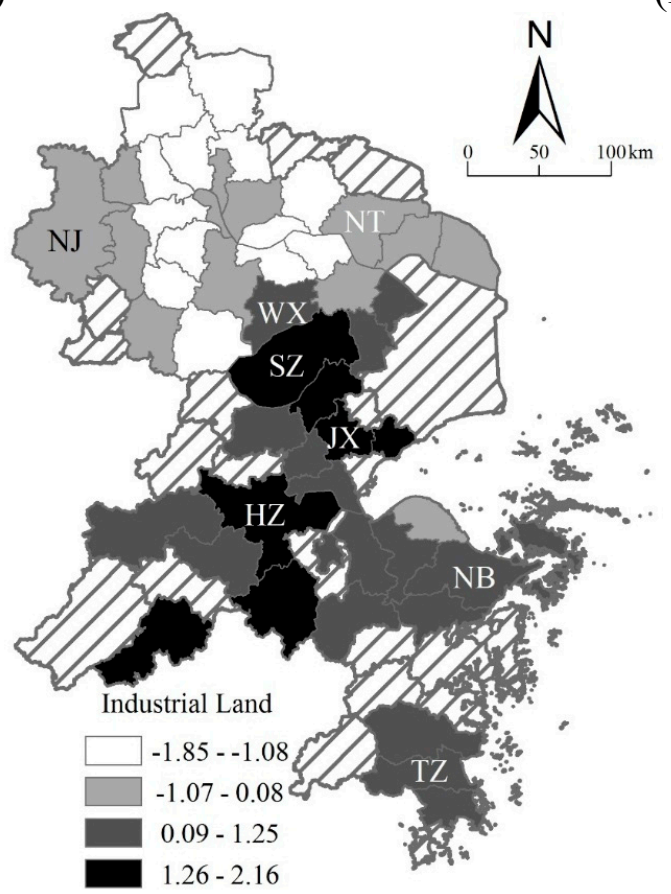

(C)

Figure 4. Hot spots of urban land use change in 51 sample cities, 2000 to 2005. Note: $\mathrm{NJ}=$ Nanjing, $\mathrm{HZ}=$ Hangzhou, $\mathrm{SZ}=$ Suzhou, $\mathrm{WX}=$ Wuxi, NB $=$ Ningbo, $\mathrm{NT}=$ Nantong, $\mathrm{JX}=$ Jiaxing, $\mathrm{TZ}=$ Taizhou. (A) Comprehensive land change. (B) Residential land change. (C) Industrial land change. 


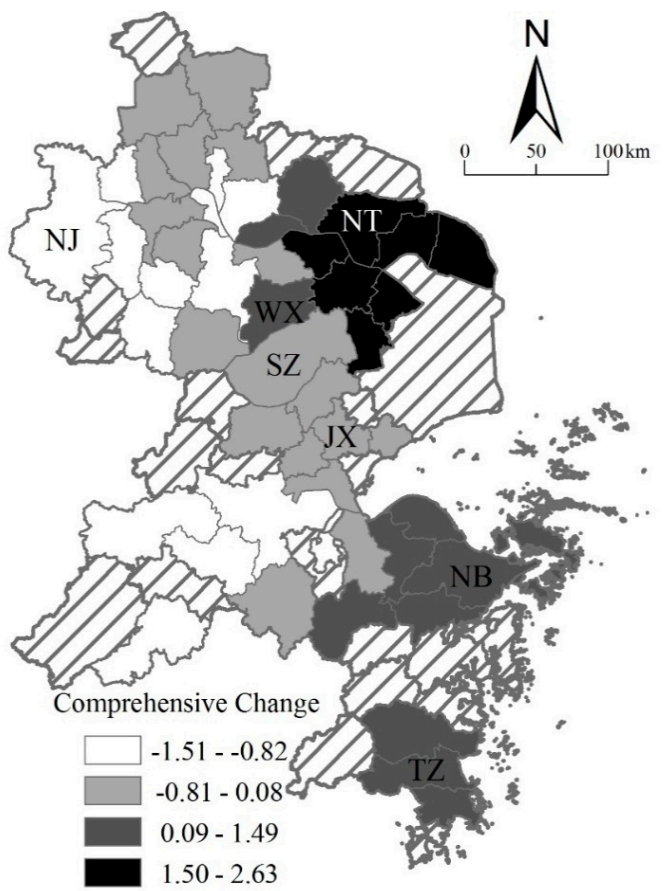

(A)

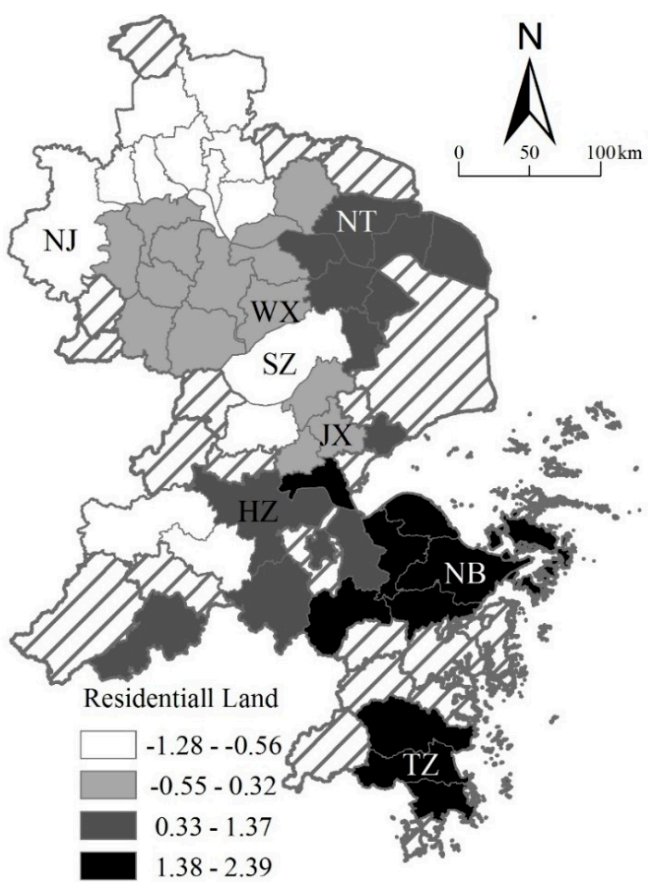

(B)

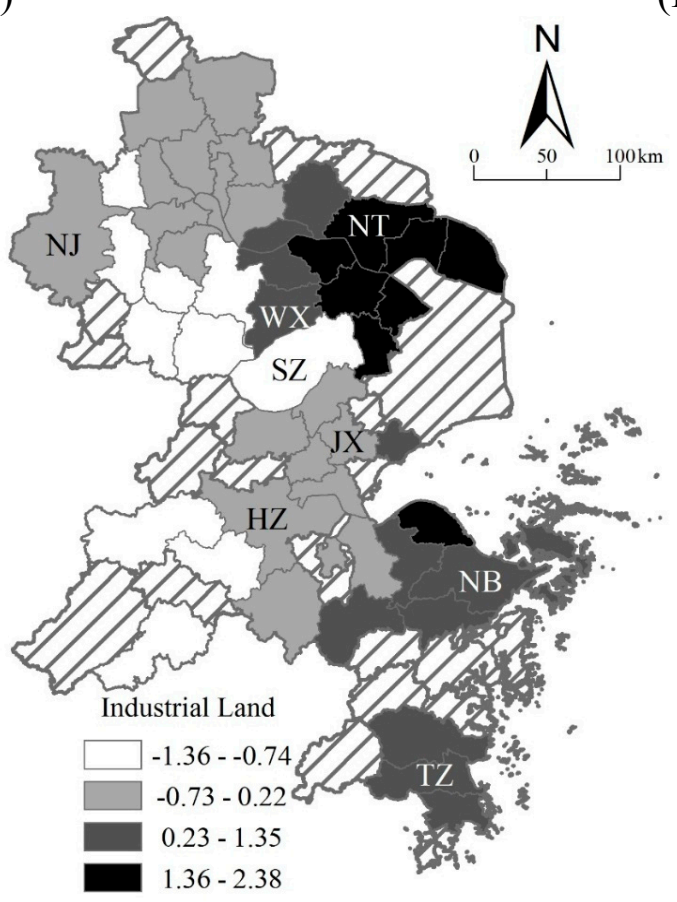

(C)

Figure 5. Hot spots of urban land use change in 51 sample cities, 2005 to 2010. Note: $\mathrm{NJ}=$ Nanjing, $\mathrm{HZ}=$ Hangzhou, $\mathrm{SZ}=$ Suzhou, $\mathrm{WX}=$ Wuxi, NB $=$ Ningbo, $\mathrm{NT}=$ Nantong, $\mathrm{JX}=$ Jiaxing, $\mathrm{TZ}=$ Taizhou. (A) Comprehensive land change. (B) Residential land change. (C) Industrial land change.

(a) Since 2000, urban land use structure in the YRD has been maturing gradually. A shift in significant hotspots can be observed. For example, while the Northern ZJ (around Hangzhou) is a hotspot in 2000 to 2005, the region of Suzhou-Nantong is a hotspot in 2005 to 2010. There are 
more residential hot spots than industrial ones in the 51 sample cities, which indicate the relatively concentrated growth of residential land and the widespread sprawl of industrial land;

(b) During 2000 to 2005, the hot spots of residential land are mainly located at the junction of Suzhou-Jiaxing-Hangzhou (Sujiahang) expressway, followed by Nanjing. Outside these high value areas $(\geq 0.9)$ are the median value $(0.18$ to 0.89$)$ and the low value $(\leq 0.17)$ areas, which correspond to a core-periphery structure. The two hotspots of industrial land are Suzhou and Hangzhou. We can also observe a more significant core-periphery structure in the region of Northern ZJ;

(c) During 2005 to 2010, hot spots of residential land located at Hangzhou have become weaker, along with Nanjing. Instead, hot spots at Ningbo and Taizhou have emerged. Hot spots of industrial land located at Hangzhou, Suzhou and their surrounding cities have almost disappeared. Noticeably, a zonal hot spot has grown from Qidong-Haimen, through Changshu-Taicang, to Kunshan surrounding the core of Shanghai. Additionally, the inland cities have a decreasing number of active spots than the coastal cities during this period.

\subsection{Driving Forces of Urban Land Expansion}

To some extent, the process of globalization, marketization, decentralization and urbanization in the YRD could adequately explain the urban land expansion during the transition era, with three adjusted $R$-squared values of $0.87,0.78$, and 0.74 , respectively (Table 6). First, from the perspective of globalization and marketization, we find that the coefficients of FDI are significant at $90 \%, 95 \%$ and 90\% levels for the overall built-up area, the industrial land, and the residential land respectively. The factor of labor has significant coefficients for the whole built-up expansion and industrial land change at $99 \%$ and $95 \%$ levels. This signifies that the deepening new international division of labor (NIDL) promoted by the formation of global production networks (GPNs) has resulted in the transformation of regional economy from an industrial composition into a value-added hierarchy. As a result, not only have the local economy structures transformed drastically, but also the urban land use structures of cities in the YRD. For the residential land change, the values are not as significant as expected and are negative, which signifies that people might be working in one city without actually living there, and thus contributing to the "jobs-housing imbalance" [70].

Table 6. Result of panel data regressions.

\begin{tabular}{ccccccc}
\hline \multirow{2}{*}{ Variable } & \multicolumn{2}{c}{ Built-up Areas Expansion } & \multicolumn{2}{c}{ Residential Land Change } & \multicolumn{2}{c}{ Industrial Land Change } \\
\cline { 2 - 7 } & Coefficient & $\boldsymbol{t}$-Statistic & Coefficient & $\boldsymbol{t}$-Statistic & Coefficient & $\boldsymbol{t}$-Statistic \\
\hline Ln (FDI) & 0.06 & $1.63^{*}$ & 0.11 & $2.34^{* *}$ & 0.09 & $1.61^{*}$ \\
Ln (Labor) & 0.09 & $3.67^{* * *}$ & -0.09 & -0.83 & 0.07 & $1.77^{* *}$ \\
Ln (DZs) & 0.18 & $3.32^{* * *}$ & -0.06 & -0.83 & 0.30 & $3.55^{* * *}$ \\
Ln (Policy) & 0.70 & $4.11^{* * *}$ & 0.88 & $3.85^{* * *}$ & 0.52 & $1.88^{*}$ \\
Ln (Citizens) & 0.71 & $12.99^{* * *}$ & 0.89 & $12.37^{* * *}$ & 0.46 & $5.24^{* * *}$ \\
Ln (Job-housing) & 0.02 & 0.38 & 0.16 & $2.86^{* * *}$ & 0.15 & $2.14^{* *}$ \\
\hline
\end{tabular}


Table 6. Cont.

\begin{tabular}{|c|c|c|c|c|c|c|}
\hline \multirow{2}{*}{ Variable } & \multicolumn{2}{|c|}{ Built-up Areas Expansion } & \multicolumn{2}{|c|}{ Residential Land Change } & \multicolumn{2}{|c|}{ Industrial Land Change } \\
\hline & Coefficient & $t$-Statistic & Coefficient & $t$-Statistic & Coefficient & $t$-Statistic \\
\hline \multicolumn{7}{|c|}{ Region impact } \\
\hline $\operatorname{Ln}(F D I) \times$ Sunan & 0.21 & $4.19^{* * *}$ & 0.11 & $1.67^{*}$ & 0.17 & $2.13^{* *}$ \\
\hline Ln $($ Labor $) \times$ Sunan & 0.02 & 0.80 & 0.02 & 0.81 & 0.02 & 0.75 \\
\hline Ln $($ FDI $) \times$ Zhebei & 0.10 & $2.31^{* *}$ & -0.02 & -0.4 & 0.01 & 0.14 \\
\hline Ln (Labor) $\times$ Zhebei & 0.06 & $4.91^{* * *}$ & 0.02 & 1.24 & 0.05 & $2.36^{* *}$ \\
\hline \multicolumn{7}{|c|}{ Administration impact } \\
\hline Ln $(F D I) \times$ Prefecture & -0.21 & $-5.55^{* * *}$ & -0.28 & $-5.58^{* * *}$ & -0.05 & -0.73 \\
\hline $\begin{array}{c}\text { Ln }(\text { Labor }) \times \\
\text { Prefecture }\end{array}$ & 0.22 & $10.75^{* * *}$ & 0.28 & $10.72^{* * *}$ & 0.19 & $5.94^{* * *}$ \\
\hline Adjusted $R^{2}$ & \multicolumn{2}{|c|}{0.868538} & \multicolumn{2}{|c|}{0.779129} & \multicolumn{2}{|c|}{0.737394} \\
\hline Durbin-Watson stat & \multicolumn{2}{|c|}{1.961137} & \multicolumn{2}{|c|}{2.35877} & \multicolumn{2}{|c|}{1.858222} \\
\hline
\end{tabular}

Note: ${ }^{* * *}$ Significant at 0.01 level; ${ }^{* *}$ Significant at 0.05 level; ${ }^{*}$ Significant at 0.1 level.

Second, from the decentralization perspective, in line with the findings of previous studies $[14,33,62]$, "development zones" (DZs) have significant and positive impact on both the whole built-up area expansion and industrial land change. The insignificant impact of DZs on residential land change implies higher density of industries and a worse habitat environment. Along with the competition for local development, government policy and institutional changes have more influences on urban land structural changes, particularly the change of residential land (Table 6). These results imply that structural changes in urban space have facilitated the adjustment of urban land as a proactive strategy of city competition.

Third, since the 1980s, urbanization has greatly flourished urban real estate markets in the YRD. The increase of total housing construction area from 138.6 million square meters in 1984 to 347.6 million square meters in 1995-with the urban settlements getting doubled from about 21 million to about 44 million-has consequently accelerated the increase in urban residential land. The regression results (Table 6) also indicate that the number of "population", as an influencing factor of urbanization, has significant impact on the growth of built-up area $(c=0.71)$, residential land $(c=0.89)$, and industrial land $(c=0.46)$.

The results of this research indicate that for sustainable growth of residential and industrial land, “jobs-housing" relationship is a fundamental influencing factor [71]. With massive investment in urban transport infrastructure since the early 1990s, residential land has extended into suburbs or counties, which further has pushed the industrial land towards the outlying urban locations $[33,72,73]$. Another important finding is that the impact of the global market force, reflected by the FDI, on the urban land expansion in Southern JS is the greatest, implying a clustered and uneven development pattern in the YRD. The influence of labor is significant $(p<0.01)$ in Northern ZJ but insignificant in Southern JS, especially for industrial land expansion. In other words, the labor-intensive industries still play a major role and have a greater effect on urban land use structure in Northern ZJ than in Southern JS.

Finally, in terms of the administration level, both FDI and labor have significant impact on urban land expansion, especially in prefectural level cities. Interestingly, while FDI has negative impact, labor exerts positive impact. The underlying reason for this could be attributed to two interrelated aspects (a) the strict control on urban land by the government in prefectural level cities and their sub-districts, 
and (b) a little lower stringency in the county level cities that has been driving foreign enterprises' manufacturing units to be spatially located in counties and their headquarters in the prefectural districts. Due to this, the amount of FDI is high in prefectural cities with little change in urban land. With the urban land increase, the residential land growth in prefectural level cities has a more significant coefficient of labor than the whole YRD region. It implies that people tend to live in the prefectural districts while working in county level cities or even counties.

\subsection{Significance of Geographical Location and Administrative Hierarchy in Urban Land Expansion}

This section analyzes how different dynamics of urban land expansion are sensitive to the geographical location and hierarchical structure of China's urban administrative system. By applying GTWR and spatial regime models, we further produce, in a more rigorous multi-variant environment, a series of coefficients for cities located in different regions (Table 7) and two sets of comparable coefficients dedicated to each level of cities (Table 8).

Table 7. GTWR parameter estimate summaries.

\begin{tabular}{|c|c|c|c|c|c|c|}
\hline \multirow{2}{*}{ Variables } & \multicolumn{2}{|c|}{ Built-up Areas } & \multicolumn{2}{|c|}{ Residential Land } & \multicolumn{2}{|c|}{ Industrial Land } \\
\hline & Mean & Positive & Mean & Positive & Mean & Positive \\
\hline \multicolumn{7}{|c|}{ Southern Jiangsu (Observations $=153)$} \\
\hline $\operatorname{Ln}(\mathrm{FDI})$ & 0.15 & $81.05 \%$ & 0.18 & $72.55 \%$ & 0.16 & $76.47 \%$ \\
\hline Ln (Labor) & 0.57 & $79.74 \%$ & 0.83 & $83.66 \%$ & 0.81 & $85.62 \%$ \\
\hline $\operatorname{Ln}(\mathrm{DZs})$ & 0.34 & $69.93 \%$ & -0.08 & $43.79 \%$ & 0.26 & $67.97 \%$ \\
\hline Ln (Policy) & -0.10 & $49.02 \%$ & -0.72 & $7.19 \%$ & -0.54 & $30.07 \%$ \\
\hline Ln (Citizens) & 0.28 & $75.82 \%$ & 0.20 & $72.55 \%$ & 0.05 & $57.52 \%$ \\
\hline Ln (Job-housing) & -0.31 & $30.72 \%$ & -0.72 & $13.07 \%$ & -1.04 & $6.54 \%$ \\
\hline \multicolumn{7}{|c|}{ Central Jiangsu $($ Observations $=117)$} \\
\hline $\operatorname{Ln}(\mathrm{FDI})$ & -0.02 & $47.01 \%$ & -0.03 & $47.86 \%$ & -0.05 & $38.46 \%$ \\
\hline Ln (Labor) & 0.55 & $83.76 \%$ & 1.44 & $94.02 \%$ & 1.28 & $98.29 \%$ \\
\hline $\operatorname{Ln}(\mathrm{DZs})$ & 0.99 & $96.58 \%$ & 0.45 & $92.31 \%$ & 0.82 & $88.03 \%$ \\
\hline Ln (Policy) & 0.40 & $88.03 \%$ & -0.13 & $23.93 \%$ & -0.12 & $76.92 \%$ \\
\hline Ln (Citizens) & -0.08 & $47.86 \%$ & -0.68 & $26.50 \%$ & -0.64 & $11.97 \%$ \\
\hline Ln (Job-housing) & -0.63 & $16.24 \%$ & -1.16 & $5.13 \%$ & -1.28 & $2.56 \%$ \\
\hline \multicolumn{7}{|c|}{ Northern Zhejiang $($ Observations $=189)$} \\
\hline $\operatorname{Ln}(\mathrm{FDI})$ & 0.12 & $78.84 \%$ & 0.06 & $64.02 \%$ & 0.21 & $77.25 \%$ \\
\hline Ln (Labor) & 0.03 & $51.85 \%$ & -0.03 & $53.44 \%$ & -0.01 & $52.38 \%$ \\
\hline $\operatorname{Ln}(\mathrm{DZs})$ & 0.57 & $89.42 \%$ & 0.40 & $70.37 \%$ & 0.40 & $85.71 \%$ \\
\hline Ln (Policy) & 0.21 & $54.50 \%$ & -0.77 & $35.45 \%$ & -0.45 & $21.69 \%$ \\
\hline Ln (Citizens) & 0.52 & $84.13 \%$ & 0.82 & $83.07 \%$ & 0.65 & $91.01 \%$ \\
\hline Ln (Job-housing) & 0.12 & $72.49 \%$ & 0.19 & $70.90 \%$ & 0.22 & $64.02 \%$ \\
\hline Bandwidth & \multicolumn{2}{|c|}{0.4661} & \multicolumn{2}{|c|}{0.5047} & \multicolumn{2}{|c|}{0.6389} \\
\hline Adjusted $R^{2}$ & \multicolumn{2}{|c|}{0.9896} & \multicolumn{2}{|c|}{0.9559} & \multicolumn{2}{|c|}{0.9289} \\
\hline
\end{tabular}

Note: "Mean" denotes the average value of all the coefficients. "Positive" denotes the proportion of positive ones.

The results imply that the urban land expansion mechanisms of cities in the YRD are sensitive to the geographical location. In different regions, the selected factors have dissimilar impacts on urban land 
expansion (Table 7). For instance, FDI apparently has more positive influence on urban land expansion in Southern JS and Northern ZJ than in Central JS. This result confirms that the developed cities with better infrastructure systems have yielded more success in drawing FDI and that the power of globalization is allocated by the level of development in the YRD. By contrast, there are more positive coefficients of labor in Central JS than the other two regions. This result demonstrates that increasing interest of labor to work in developed cities is leading to a frequent labor migration from the less developed regions of Central JS. A similar situation has also appeared for variables of DZ and government policy. This implies that urban growth and land expansion in the developing cities rely on both the local and upper-level government to a greater extent. Population growth is evidently a positive impetus after urban land expansion in China [43]. Notably, the effect of permanent citizens, which is characterized by the population living in the urban area for six months or longer, is more intensive for urban land expansion in developed Southern JS and Northern ZJ than Central JS. The job-housing relationship is more positive in Northern $\mathrm{ZJ}$, where the private economies are more active.

Table 8. Results of spatial regime model.

\begin{tabular}{ccccccc}
\hline \multirow{2}{*}{ Variables } & \multicolumn{2}{c}{ Build-up Areas } & \multicolumn{2}{c}{ Residential Land } & \multicolumn{2}{c}{ Industrial Land } \\
\cline { 2 - 7 } & Prefecture & County & Prefecture & County & Prefecture & County \\
\hline Ln (FDI) & $0.05^{* *}$ & $0.14^{* * *}$ & 0.01 & $0.15^{* * *}$ & $0.28^{* * *}$ & $0.11^{* * *}$ \\
Ln (Labor) & $0.12^{*}$ & $0.59^{* * *}$ & $0.18^{*}$ & $0.64^{* * *}$ & $0.34^{* * *}$ & $0.54^{* * *}$ \\
Ln (DZs) & $0.24^{* * *}$ & $0.08^{*}$ & $0.50^{* * *}$ & $-0.22^{* *}$ & $0.19^{*}$ & $0.35^{* * *}$ \\
Ln (Policy) & $0.17^{* *}$ & $-0.11^{*}$ & $0.17^{*}$ & $-0.58^{* * *}$ & $0.14^{*}$ & $-0.39^{* * *}$ \\
Ln (Citizens) & $0.83^{* * *}$ & $0.27^{* * *}$ & $0.27^{* *}$ & $0.24^{* *}$ & $0.75^{* * *}$ & $0.13^{*}$ \\
Ln (Job-housing) & $0.10^{* * *}$ & $-0.09^{*}$ & 0.01 & -0.01 & $0.23^{* * *}$ & 0.02 \\
\hline Adjusted $R^{2}$ & \multicolumn{2}{c}{0.844425} & & 0.637504 & 0.755844
\end{tabular}

Table 8 reports the spatial regime model outputs of estimation of parameters for two different administrative hierarchies. Coefficients of all variables for two regimes have different values, which implies that the urban land expansion mechanisms of cities are sensitive to administrative hierarchies, in addition to the geographical location. For prefecture cities, we find that the build-up area expansion is more sensitive to variables such as the number of permanent citizens and the job-housing relation. The model of residential land change indicates that the DZs have greatly promoted the growth of residential land areas. The industrial land change is sensitive to all variables, in which the government impact of DZs and policy are only marginally positive.

For county level cities, we have observed that there is an apparent dissimilarity between the prefectures. The build-up area expansion, as well as the growth of residential land and industrial land, are most influenced by the global market. Results shown in Table 8 imply that the FDI and Labor have significant positive influence on urban land expansion in the county level cities, demonstrating active economy in the county level cities of the YRD [40]. The coefficient of DZs is significantly negative for residential land growth but positive for industrial land, which means that the establishment of DZs in county level cities is largely to increase GDP and is still far from the integration of industrial and urban 
functions [74]. The urban land expansion in county level cities is less sensitive to the variables of urbanization, in which only the number of citizens is marginally positive.

\section{Discussion}

Regarding urban land expansion and its driving mechanisms, several important discussion points have emerged from the findings of this paper. First, the overall level urban expansion in the Yangtze River Delta (YRD) (in the period 2000 to 2010) is characterized by a relatively consistent growth in residential land, and a triple growth rate in industrial land, demonstrating the industrialization driven urban development path of the overall region. While these patterns could be similar to the spatial structural changes in cities across the world [12], unlike the cities in the Western world, a large number of sub-regional spatial differences exist in the YRD. A deeper spatial analysis reveals that while cities in the higher level areas, such as the less developed Central Jiangsu (JS), are experiencing rapid increase in residential land and relatively slow industrial development, the cities in the lower level regions, such as the Northern Zhejiang (ZJ), are witnessing rapid industrialization and a sharp increase in industrial land. While in the most developed Southern JS, urban expansion is characterized by a balanced growth of residential and industrial land. In brief, while the prefectural level cities are transforming from production to service-based, the county level ones still focus on industrialization. The transformations in the YRD, as observed in the findings of this research, could be largely attributed to two aspects: (i) as the prefectural level cities are highly urbanized, the local governments have been focusing on de-concentration of manufacturing, and providing more land for neighborhood development and service based centres; and (ii), the policy of "Increase Power of the County" (qiangxian kuoquan) and the development competition between county level cities and prefectures has recently led to the allocation of more industrial land in the county level cities [75].

Second, the cities in the developed areas (e.g., Southern JS and Northern ZJ) are gradually optimizing their urban land use structure to be more coordinated and compact. On the other hand, the continuously dominant urban land expansion in the less developed Central JS is not only leading to simple and low-density land use patterns but also, to some extent, is widening the gap between the region and the developed areas in terms of attracting economic investment. As emphasized by the previous literature [22], while the patterns of compact development, as seen in the developed areas of the YRD, can promote sustainable land use, the sprawl and low-density patterns of the less developed areas can reinforce unsustainable urban land use in the YRD. An in-depth analysis of the evolution of urban land expansion further discloses an emerging core-periphery spatial pattern in the YRD. The hot spots of urban land use change have been concentrated at the core cities, which are more developed or have higher administrative hierarchies, in the initial stage. Then, the hot spots have gradually spread to counties in the surrounding periphery. With the increasing urbanization and industrialization in the past decade, and the narrowing gaps between both different administration and development levels, urban land expansion in the YRD shows a convergence trajectory and regional integration.

Third, by integrating the global market functions to the existing framework [11,50], and incorporating the six influencing factors, our conceptual framework can not only contribute to an improved understanding of the transitional nature of structural changes in China's urban land expansion, but also use Western theories to explain China's urban development. Specifically, as an emerging global city 
region in China and the world's sixth-largest economic center, the YRD region has been facing fierce global and regional competition for investment from the Transnational Corporations (TNCs) [75]. A variety of development zones (DZs) and new towns are being established to attract economic investment and absorb skilled migrants [57]. By the end of 2010, 132 provincial and national DZs were established in the 51 sample cities, which account for about 1/10th of the country. Due to this increasing investments, cities in this region have been witnessing large migration of labor from rural areas [76], which consequently has accelerated urban land expansion. In addition to the active market in the YRD, governmental policies have also been playing important roles in the processes of urbanization and industrialization [35]. The central development strategies, such as the integration plan of the YRD, the modernization plan of the Southern JS, and the development plans of the Coastal JS and ZJ, have obviously accelerated urban expansion in the YRD, although the policies need to be more conducive to promoting sustainable regional development. Due to the influence of these different forces, urban population has increased in the YRD, which in turn has accelerated the process of urbanization and greatly flourished the urban real estate markets. The total urban settlements in the 51 sample cities have increased from about 31 million in 2000 to 49 million in 2010, with the housing construction area almost doubling from 662 million square meters to about 1230 million square meters. Similarly, with massive investment in regional transport infrastructure since the early 1990s [1], the jobs-housing relationship in the YRD has changed and led to the restructuring of the current urban land use.

More generally, this finer-scale research reveals that in comparison to Western countries, urban land expansion mechanisms in China are sensitive to both development changes and administrative hierarchies. The reforms are implemented through the central government-directed top-down process and are largely beyond the control of local governments, although policy formation involves central-local interactions [43]. The process of industrialization, however, takes place within a more bottom-up approach in the YRD, particularly in the developed Southern JS [59]. Consequently, the driving forces of the global market and urban institutions are more significant in active county level cities in Southern JS and higher hierarchical prefectures than the other counterparts. The urban growth and land expansion in less active developing cities, on the other hand, rely on both the local and upper-level government to a great extent. Due to the regional inequality in both the urban economy and the standard of living of the residents [77], urban land expansion is not so sensitive to the urbanization process in the less developed and urbanized county level cities.

These findings imply that the governments need to better balance the allocation of capital and resources. A list of guidelines should be developed to promote sustainable urban land use instead of allowing the urban land expansion driven by natural forces. Admittedly, sustainable urban development (SUD) strategies, such as arable land and ecology protection, economical and intensive land use, coordination of economy, food security, have already been at the centre of China's policy [76]. However, the current land-use policies target different problems, which unexpectedly result in limited success or even in some cases, adverse consequences [4]. For the sustainable development of urban land, two policy recommendations are proposed. First, the local governments need to better balance the allocation of capital and resources at the finer scale. To do so, terms and conditions for siting industrial projects should be more rigorous in the active county level cities of Southern JS and Northern ZJ. For instance, ZJ provincial government has established a market to trade land development rights across localities in the province. This has helped to evade the constraints of the construction land quota in the fast developing 
regions and protect the ecological land and farmland in the agricultural and/or ecological counties of ZJ [78]. More of such kinds of initiatives could not only lead to controlling the rapid industrial land expansion and improving land use density, but also coordinating the land use structure in the less developed Central JS as well as narrowing the development gaps within the region. Second, as core cities (both the developed and higher hierarchy) have been playing leading roles in regional urban land use, further reforms might drive sustainable development of these cities and their surrounding areas. For example, the redevelopment or renewal of the initially allocated state-owned land by employing land leasing fees in urban centers, the rigorous control of the real estimate market in higher hierarchical prefectural cities, and the mixed-use of urban land instead of specific single land use zoning (e.g., residential and commercial/office, industrial and storage etc.) cannot only help to achieve SUD but also address the challenges associated with rapid urban land expansion.

\section{Conclusions}

This paper has studied the urban expansion and structural change in the YRD, and examined the driving forces based on the developed conceptual framework. Drawing on the accounts of central findings of this research, we find that there is a strong case for claims of regional inequality in this urban land expansion picture. We can make this conclusion with reference to the notions of sustainable land use, whose conditions are not met [24]. We can also argue that the findings of this research provide a rich narrative and novel perspectives to the debates on urban land expansion in regions, by capturing regional temporal and spatial patterns of changes in urban land use and its driving forces in the YRD region.

The research has several policy and theoretical implications. First, the outcomes of this research could provide immense foresight and empirical bases for the "National New-type Urbanization Plan (NNUP)", which aims to contribute to regional land management and promote sustainable urban development in China. This study also attempts to provide an empirical foundation so as to improve policymakers' understanding of the nature of interactions of these contested phenomena as basis for evolving appropriate policies to mitigate the challenges involved. Second, our conceptual framework by integrating the market function to the framework on the transitional nature of China's development cannot only better describe China's urban restructuring process, but also assist in using Western theories to explain China's urban development. Addressing and exploring the implications of multiple driving forces on urban land expansion is needed for informed decisions and to develop urban regional policies that ensure greater sustainability. Finally, this research could also be improved and extended by considering other natural indicators of urban development, such as topography as well as the influence of urban land use inequality on regional industrial development.

\section{Acknowledgments}

We would like to acknowledge the funding of the National Natural Science Foundation of China (41329001; 41130750; 41201111) and Ford Foundation. We would also like to express our great gratitude to Bo Huang at CUHK for his generous help with the Matlab package. 


\section{Author Contributions}

Jinlong Gao was responsible for the data collection and analysis. Jinlong Gao and Yehua Dennis Wei contributed to the conceptual development and the research design. Jinlong Gao, Yehua Dennis Wei and Komali Yenneti wrote the paper. Yehua Dennis Wei and Wen Chen provided guidance and suggestions. All authors have read and approved the final manuscript.

\section{Conflicts of Interest}

The authors declare no conflict of interest.

\section{References}

1. Zhang, H.; Uwasu, M.; Hara, K.; Yabar, H. Sustainable urban development and land use change-A case study of the Yangtze River Delta in China. Sustainability 2011, 3, 1074-1089.

2. Tan, R.; Wang, R.; Sedlin, T. Land-development offset policies in the quest for sustainability: What can China learn from Germany? Sustainability 2014, 6, 3400-3430.

3. Xie, H.; Zou, J.; Jiang, H.; Zhang, N.; Choi, Y. Spatiotemporal Pattern and Driving Forces of Arable Land-Use Intensity in China: Toward Sustainable Land Management Using Emergy Analysis. Sustainability 2014, 6, 3504-3520.

4. Bai, X.; Shi, P.; Liu, Y. Realizing China's urban dream. Nature 2014, 509, 158-160.

5. Shafizadeh-Moghadam, H.; Helbich, M. Spatiotemporal variability of urban growth factors: A global and local perspective on the megacity of Mumbai. Int. J. Appl. Earth Obs. Geoinf. 2015, 35, 187-198.

6. Mcgee, T.G.; Lin, G.C.S.; Marton, A.M.; Wang, M.Y.L.; Wu, J. China's Urban Space: Development under Market Socialism; Routledge: London, UK, 2007.

7. Wu, K.-Y.; Zhang, H. Land use dynamics, built-up land expansion patterns, and driving forces analysis of the fast-growing Hangzhou metropolitan area, eastern China (1978-2008). Appl. Geogr. 2012, 34, 137-145.

8. Xu, J.; Liao, B.; Shen, Q.; Zhang, F.; Mei, A. Urban Spatial Restructuring in Transitional Economy-Changing Land Use Pattern in Shanghai China. Chin. Geogr. Sci. 2007, 17, 19-27.

9. Anderson, G.; Ge, Y. Do economic reforms accelerate urban growth? The case of China. Urban Stud. 2004, 41, 2197-2210.

10. Schneider, A.; Seto, K.C.; Webster, D.R. Urban growth in Chengdu, Western China: Application of remote sensing to assess planning and policy outcomes. Environ. Plan. B 2005, 32, 323-345.

11. Wei, Y.D. Decentralization, marketization, and globalization: The triple processes underlying regional development in China. Asian Geogr. 2001, 20, 7-23.

12. Wu, W.; Zhao, S.; Zhu, C.; Jiang, J. A comparative study of urban expansion in Beijing, Tianjin and Shijiazhuang over the past three decades. Landsc. Urban Plan. 2015, 134, 93-106.

13. Aguilar, A.G.; Ward, P.M. Globalization, regional development, and mega-city expansion in Latin America: Analyzing Mexico City's periurban hinterland. Cities 2003, 20, 3-21.

14. Li, H.; Wei, Y.D.; Liao, F.H.; Huang, Z. Administrative hierarchy and urban land expansion in transitional China. Appl. Geogr. 2015, 56, 177-186. 
15. Sassen, S. Losing Control? Sovereignty in An Age of Globalization; Stanford University Press: Redwood City, CA, USA, 1996.

16. Mittelman, J. Rethinking the international division of labour in the context of globalization. Third World Q. 1995, 16, 273-295.

17. Aguilar, A.G. Mexico City growth and regional dispersal: the expansion of largest cities and new spatial forms. Habitat Int. 1999, 23, 391-412.

18. Mollenkopf, J.; Castells, M. (Eds.) Dual City: The Restructuring of New York; Russell Sage: New York, NY, USA, 1991.

19. Sernau, S. Economies of Exclusion: Economic Change and the Global Underclass. In At the Crossroads of Development. Transnational Challenges to Developed and Developing Societies; Behar, J.E., Cuzan, A.G., Brill, E.J., Eds.; BRILL: Leiden, The Netherlands, 1997.

20. Camagni, R.; Gibelli, C.M.; Rigamonti, P. Urban mobility and urban form: the social and environmental costs of different patterns of urban expansion. Ecol. Econ. 2002, 40, 199-216.

21. CNU. Charter of the New Urbanism, 2002. Available online: http://cnu.org/sites/default/files/chart er_english.pdf (accessed on 29 July 2015).

22. Ligmann-Zielinska, A.; Church, R.; Jankowski, P. Sustainable urban land use allocation with spatial optimization. In Proceedings of the 8th International Conference on Geocomputation, Ann Arbor, MI, USA, 31 July-3 August 2005.

23. Newman, P.W.; Kenworthy, J.R. The land use-transport connection: An overview. Land Use Policy 1996, 13, 1-22.

24. Song, Y.; Knaap, G.J. New urbanism and housing values: A disaggregate assessment. J. Urban Econ. 2003, 54, 218-238.

25. Li, L.; Sato, Y.; Zhub, H. Simulating spatial urban expansion based on a physical process. Landsc. Urban Plan. 2003, 64, 67-76.

26. Stewart, J. Hot 'Lanta's Urban Expansion and Cultural Landscape Change. Geogr. Rev. 1999, 89, $132-140$.

27. Hise, G. Nature's workshop' industry and urban expansion in Southern California, 1900-1950. J. Hist. Geogr. 2001, 27, 74-92.

28. Bradshaw, T.; Muller, B. Impacts of rapid urban growth on Farmland conversion: Application of new regional land use policy models and geographical information systems. Rural Sociol. 1998, 63, $1-25$.

29. Cervero, R. Road expansion, urban growth, and induced travel. J. Am. Plan. Assoc. 2003, 69, 145-163.

30. Northrup, M.; Duket, L. Smart Growth: Designating Priority Funding Areas; Maryland Office of Planning: Annapolis, MD, USA, 1997.

31. Grout, A.C.; Jaeger, K.W.; Plantinga, J.A. Land-use regulations and property values in Portland, Oregon: A regression discontinuity design approach. Reg. Sci. Urban Econ. 2011, 41, 98-107.

32. Gao, J.; Wei, Y.D.; Chen, W.; Chen, J. Economic transition and urban land expansion in Provincial China. Habitat Int. 2014, 44, 461-473.

33. Liu, Y.; Yue, W.; Fan, P.; Song, Y. Suburban residential development in the era of market-oriented land reform: The case of Hangzhou, China. Land Use Policy 2015, 42, 233-243.

34. Liu, Y.; Yue, W.; Fan, P. Spatial determinants of urban land conversion in large Chinese cities: A case of Hangzhou. Environ. Plan. B 2011, 38, 706-725. 
35. Zhang, Q.; Wallace, J.; Deng, X.; Seto, K.C. Central versus local states: Which matters more in affecting China's urban growth? Land Use Policy 2014, 38, 487-496.

36. Friedmann, J. Four theses in the study of China's urbanization. Int. J. Urban Reg. Res. 2006, 30, 440-451.

37. Zhang, T. Urban development and a socialist pro-growth coalition in Shanghai. Urban Aff. Rev. 2002, 37, 475-499.

38. Zhang, S. Land-centered urban politics in transitional China-Can they be explained by Growth Machine Theory? Cities 2014, 41, 179-186.

39. Wei, Y.D. Urban land use transformation and determinants of urban land use size in China. GeoJournal 1993, 30, 435-440.

40. Zhang, J.; Wu, F. China's changing economic governance: Administrative annexation and the reorganization of local governments in the Yangtze River Delta. Reg. Stud. 2006, 40, 3-21.

41. Ding, C.; Lichtenberg, E. Land and urban economic growth in China. J. Reg. Sci. 2011, 51, $299-317$.

42. Ding, C. Urban spatial development in the land policy reform era: Evidence from Beijing. Urban Stud. 2004, 41, 1889-1907.

43. Wei, Y.D. Restructuring for growth in urban China: Transitional institutions, urban development, and spatial transformation. Habitat Int. 2012, 36, 396-405.

44. Lin, G.C. Peri-urbanism in globalizing China: A study of new urbanism in Dongguan. Eurasian Geogr. Econ. 2006, 47, 28-53.

45. Gao, J.; Li, S. Detecting spatially non-stationary and scale-dependent relationships between urban landscape fragmentation and related factors using geographically weighted regression. Appl. Geogr. 2011, 31, 292-302.

46. Liao, F.H.; Wei, Y.D. Modeling determinants of urban growth in Dongguan, China: A spatial logistic approach. Stoch. Environ. Res. Risk Assess. 2014, 28, 801-816.

47. Luo, J.; Wei, Y.D. Modeling spatial variations of urban growth patterns in Chinese cities: The case of Nanjing. Landsc. Urban Plan. 2009, 91, 51-64.

48. Wei, Y.D.; Li, W. Reforms, globalization, and urban growth in China: The case of Hangzhou. Eurasian Geogr. Econ. 2002, 43, 459-475.

49. Liu, J.; Zhan, J.; Deng, X. Spatio-temporal patterns and driving forces of urban land expansion in China during the economic reform era. AMBIO J. Hum. Environ. 2005, 34, 450-455.

50. Wei, Y.D. Regional inequality in China. Prog. Hum. Geogr. 1999, 23, 49-59.

51. Deng, X.; Huang, J.; Rozelle, S.; Uchida, E. Growth, population and industrialization, and urban land expansion of China. J. Urban Econ. 2008, 63, 96-115.

52. Wang, E.; Song, J.; Xu, T. From "spatial bond" to "spatial mismatch": An assessment of changing jobs-housing relationship in Beijing. Habitat Int. 2011, 35, 398-409.

53. Loo, B.P.; Chow, A.S. Jobs-housing balance in an era of population decentralization: An analytical framework and a case study. J. Transp. Geogr. 2011, 19, 552-562.

54. Zhou, J.; Zhang, C.; Chen, X.; Huang, W.; Yu, P. Has the legacy of Danwei persisted in transformations? the jobs-housing balance and commuting efficiency in Xi'an. J. Transp. Geogr. 2014, 40, 64-76.

55. Wei, Y.D.; Leung, C.K.; Luo, J. Globalizing Shanghai: foreign investment and urban restructuring. Habitat Int. 2006, 30, 231-244. 
56. Wei, Y.D.; Leung, C.K. Development Zones, Foreign Investment, and Global City Formation in Shanghai. Growth Chang. 2005, 36, 16-40.

57. Wei, Y.D. Zone fever, project fever: Economic transition, development policy, and urban expansion in China. Geogr. Rev. 2015, 105, 156-177.

58. Shahtahmassebi, A.; Pan, Y.; Lin, L.; Shortridge, A.; Wang, K.; Wu, J.X.; Wu, D.; Zhang, J. Implications of land use policy on impervious surface cover change in Cixi County, Zhejiang Province, China. Cities 2014, 39, 21-36.

59. Zhu, J. Local growth coalition: The context and implications of China's gradualist urban land reforms. Int. J. Urban Reg. Res. 1999, 23, 534-548.

60. Wong, C.P. Central-local Relations Revisited the 1994 tax-sharing reform and public expenditure management in China. China Perspect. 2000, 31, 52-63.

61. Li, J.; Chiang, Y.-H.; Choy, L. Central-local conflict and property cycle: A Chinese style. Habitat Int. 2011, 35, 126-132.

62. Zheng, X.; Geng, B.; Wu, X.; Lv, L.; Hu, Y. Performance Evaluation of Industrial Land Policy in China. Sustainability 2014, 6, 4823-4838.

63. Taylor, P.J. World City Network: A Global Urban Analysis; Routledge: London, UK, 2004.

64. Chen, A.; Partridge, M.D. When are cities engines of growth in China? Spread and backwash effects across the urban hierarchy. Reg. Stud. 2013, 47, 1313-1331.

65. Steudler, D.; Rajabifard, A.; Williamson, I.P. Evaluation of land administration systems. Land Use Policy 2004, 21, 371-380.

66. Liao, F.H.; Wei, Y.D. Dynamics, Space, and Regional Inequality in Provincial China: A Case Study of Guangdong Province. Appl. Geogr. 2012, 35, 71-83.

67. Cravo, T.A.; Resende, G.M. Economic growth in Brazil: A spatial filtering approach. Ann. Reg. Sci. 2013, 50, 555-575.

68. MHURD. China Urban Construction Stastical Yearbook, 2000, 2005, 2010; China Planning Press: Beijing, China, 2001, 2006, 2011. (In Chinese)

69. Xu, X.Q.; Chu, D.K.Y. Modern Urban Geography; China Architecture \& Building Press: Beijing, China, 1988. (In Chinese)

70. Ding, C.; Zhao, X. Assessment of Urban Spatial-Growth Patterns in China During Rapid Urbanization. Chin. Econ. 2011, 44, 46-71.

71. Giuliano, G.; Small, K.A. Is the journey to work explained by urban structure? Urban Stud. 1993, $30,1485-1500$.

72. Yuan, F.; Wei, Y.D.; Chen, W. Economic transition, industrial location and corporate networks: Remaking the Sunan Model in Wuxi City, China. Habitat Int. 2014, 42, 58-68.

73. Zheng, S.; Fu, Y.; Liu, H. Housing-choice hindrances and urban spatial structure: Evidence from matched location and location-preference data in Chinese cities. J. Urban Econ. 2006, 60, 535-557.

74. Van Oort, F.; Burger, M.; Raspe, O. On the economic foundation of the urban network paradigm: Spatial integration, functional integration and economic complementarities within the Dutch Randstad. Urban Stud. 2010, 47, 725-748.

75. Wei, Y.D.; Liao, F.H. The embeddedness of transnational corporations in Chinese cities: Strategic coupling in global production networks? Habitat Int. 2013, 40, 82-90. 
76. Liu, Y.; Fang, F.; Li, Y. Key issues of land use in China and implications for policy making. Land Use Policy 2014, 40, 6-12.

77. Wei, Y.D.; Yu, D.; Chen, X. Scale, agglomeration, and regional inequality in provincial China. Tijdschrift voor Economische en Sociale Geografie 2011, 102, 406-425.

78. Zhang, W.; Wang, W.; Li, X.; Ye, F. Economic development and farmland protection: An assessment of rewarded land conversion quotas trading in Zhejiang, China. Land Use Policy 2014, 38, 467-476.

(C) 2015 by the authors; licensee MDPI, Basel, Switzerland. This article is an open access article distributed under the terms and conditions of the Creative Commons Attribution license (http://creativecommons.org/licenses/by/4.0/). 